\title{
Agonística e palavra
}

\author{
Agonistic and word
}

\section{Guilherme Castelo Branco}

Professor do Departamento de Filosofia da Universidade Federal do Rio de Janeiro (UFRJ), trabalha no Programa de Pós-Graduação em Filosofia, Rio de Janeiro, RJ - Brasil, e-mail: guicbranco@ig.com.br; castelobranco@ifcs.ufrj.br

\section{Resumo}

Partiremos da hipótese de que a filosofia não nasceu sob o signo da pacificação nem se desenvolveu em um mundo social regido pelo consenso. Oriunda de uma precária e frágil experiência democrática na Grécia Antiga, a tarefa maior da filosofia, desde sua origem, foi a de buscar constituir argumentos consistentes do ponto de vista da lógica do discurso e que fossem socialmente aceitos. Como pensamento e luta estão juntos, decorre disso que inexiste filosofia sem beligerância, sem rivalidade, sem disputa. O inimigo maior da filosofia, assim, não é a luta argumentativa, nem o combate teórico, tampouco o adversário da filosofia é a doxa. Nosso maior adversário não é da ordem do pensamento, em que existe e deve existir certo grau de tolerância e rivalidade entre distintos modos de perceber as coisas. A agonística entre ideias diferentes não é a verdadeira inimiga da filosofia, mas o lugar natural de seu exercício.

Palavras-chave: Agonística. Palavra. Filosofia política. Foucault. Filosofia contemporânea. 


\section{Resumé}

Selon notre hypothèse, la philosohie n'a pas eu naissance sous le signe de la pacification ni s'agrandri dans um monde social consensuel. Venue d'une précaire et fragile experiénce democratique dans la Gréce Ancienne, le travail majeur de la philosophie, dés son commencement, a eté chercher des argumentations plausibles du point de vue de la logique du discours, et socialement admises. Une fois que pensée et dispute sont ensemble, il vient que il n'existe pas philosophie sans rivalité ni dispute, et le plus grand innimi de la philosophie n'est pas la lutte théorique, ainsi comme l'adversaire de la philosophie n'est pas la doxa. En verité, notre plus grand adversaire n'est pas de l'ordre de la pensée, oú ily a et doit avoir um certain degré de tolerance et rivalité entre les différentes maniéres de conprendre les choses. L'agonistique entre des idées différents, donc, n'est pas le vrai adversaire de la philosophie, mais le lieu naturel de son exercice.

Mots-clé: Agonisme. Parole. Philosophie politique. Foucault. Philosophie contemporaine.

\section{Abstract}

Our hypothesis is that the philosophy was not born under the sign of peace or developed into a social world governed by consensus. Coming from a precarious and fragile experiment with democracy in ancient Greece, the major task of philosophy since its beginning, is to form consistent arguments from the standpoint of the logic of speech and, also, socially accepted. How thought and struggle are together, it follows that philosophy is absent without belligerency, without rivalry, without theoric dispute. The biggest enemy of philosophy is not the argumentative fight or the combat theory, nor the opponent's of philosophy is doxa. Our biggest enemy is not in the order of thought, where there should be a degree of tolerance and rivalry between different ways of perceiving things. The agonistic between different ideas is not the real enemy of philosophy, but the natural place to this exercise.

Keywords: Agonistic. Word. Political philosophy. Foucault. Contemporary philosophy.

\section{Introdução}

A relação entre palavra e cidadania recebe as mais diversas abordagens teóricas, e ela está diretamente envolvida com a questão da 
democracia e do exercício do poder, temas maiores e incontornáveis da filosofia política. Michel Foucault (1926-1984), filósofo francês contemporâneo, traz contribuições a esses temas centrais da filosofia política. Foucault define o exercício do poder como um modo de ação sobre as ações dos outros, como uma espécie de "governo", em sentido amplo, dos homens uns sobre os outros, em que está presente um elemento importante, que é a liberdade. O poder e a liberdade não se excluem. "O poder se exerce apenas sobre "sujeitos livres" e enquanto são "livres", entendendo por isso sujeitos individuais ou coletivos que têm diante de si um campo de possibilidades no qual podem ter lugar muitas condutas, reações e diversos modos de se comportar" (FOUCAULT, 1994, p. 237).

Onde inexiste a prática da liberdade, não há relações de poder: “a escravidão não é uma relação de poder quando o homem está acorrentado (trata-se, então, de uma relação física constrangedora), mas somente quando ele pode se movimentar e, no limite, fugir" (FOUCAULT, 1994, p. 238). A força e a ênfase dessa passagem devem ser levadas em consideração: a condição de exercício do poder é sempre, e acima de tudo, a liberdade. Sem liberdade, que pode acontecer durante qualquer tempo, curto ou longo, de opressão e/ou de subordinação pela violência, não há possibilidade de relação ou exercício de poder. Todo poder, por ser relacional, requer confronto entre os envolvidos, uma rivalidade que somente pode vigorar na disputa de perspectivas e de pontos de vista. Na ausência de liberdade, o que ocorre é a relação autoritária, totalitária, em condições em que existem estruturas de poder para as quais não são desejadas mudanças sociais e intelectuais ou artísticas.

O exercício de poder autoritário pode durar algum tempo, em certos casos muito tempo, mas nunca para sempre e nunca de modo absolutamente homogêneo, uma vez que é impossível que os conflitos e as agonísticas nas relações de poder cessem de existir. Para Foucault, a potência da liberdade pertence ao conteúdo ontológico do homem histórico moderno. A modernidade nada mais é que a conquista real de crescente liberdade por parte dos homens, no efetivo exercício de suas potencialidades nesse momento histórico determinado, em que se exprimem a coragem e a vontade de pensar e agir de forma independente. Como os campos de exercício do poder são determinados 
pelas múltiplas relações entre homens livres, eles decorrem sempre de uma tensão inevitável entre a diversas potências do agir humano, entre os diferentes interesses e entre as diversas formas de vida. Foucault ressalta também que a liberdade só existe de modo agonístico, na luta com tudo e com todos que possam ser percebidos como obstáculos à sua determinação específica e seus desígnios históricos. A questão que surge do confronto entre liberdade e poder é:

a relação de poder e a insubmissão da liberdade, desse modo, não podem ser separadas. O problema central do poder não é o da "servidão voluntária" (como poderíamos desejar ser escravos?): no cerne da relação de poder, "provocando-a" incessantemente, temos a reatividade do querer e a "intransigência" da liberdade. Mais que de um "antagonismo" essencial, seria melhor falar de uma "agonística" - de uma relação que é, ao mesmo tempo, de incitação recíproca e de luta; trata-se menos de uma oposição termo a termo que os bloqueia um em face do outro, e mais de uma provocação permanente.

A agonística entre liberdade e poder não é uma questão simples. A liberdade é tanto condição para o exercício do poder quanto da resistência a ele. A agonística, ou, em outros termos, toda luta individual e social pró ou contra a efetivação da liberdade, torna-se assim uma questão política incontornável, "tarefa política inerente a toda existência social" (FOUCAULT, 1994, p. 238-239).

Para Foucault, pensar a política é o mesmo que observar os afrontamentos nas relações de poder, com ênfase nas resistências e estratégias postas em jogo para ampliar o campo da liberdade. Um processo de libertação, portanto, não se limita ao campo das lutas das minorias e de classes, mas põe também em cena o estatuto da liberdade individual, uma vez que a liberdade pessoal deságua no universo da comunidade e do mundo social. Em outros termos, trata-se de reconhecer, partindo da constatação fundamental dos procedimentos postos em ação pelos Estados modernos para conhecer e dirigir a vida das pessoas, a começar por suas vidas subjetivas - o que Foucault denomina "governo por individuação" -, os modos pelos quais certos indivíduos realizam, com êxito, um deslocamento ou uma subtração em face dos saberes-poderes e das múltiplas técnicas de poder utilizadas pelas instituições e pelo Estado. 
A identidade pessoal pode ser - e é, em boa parte e para a maioria das pessoas - o resultado de uma ação institucional e estatal bem-sucedida (do ponto de vista dos dispositivos de poder, é claro). Nesse caso, o que temos é uma subjetividade assujeitada, normalizada, controlada pelas técnicas do poder. Contrapondo-se a esses processos individualizadores, por meio dos quais são internalizados certos padrões socialmente desejáveis de vida subjetiva, Foucault toma para si a palavra de ordem da recusa das formas de subjetivação que nos foram impostas durante os últimos séculos, uma recusa que se desdobra na elaboração posterior de efetivos espaços de liberdade. Cabe a nós mesmos deliberar, criar, experimentar novas formas de subjetivação.

O que está em jogo, bem entendido, são processos subjetivos e objetivos de autonomização que se opõem às técnicas de individuação e normalização dos dispositivos de poder e controle. Sob certas condições, podemos ultrapassar os limites postos de nós. Foucault é categórico: toda liberdade é conquistada e vem da superação de algum limite, como resultado de um combate calculado e estrategicamente bem-sucedido. Tem de estar em jogo uma razão estratégica libertária contrária a uma razão estratégica normalizadora, disciplinar ou biopolítica. Isso está muito distante de certa ideia equivocada de que ele estaria falando de transgressão, do caráter transgressor da liberdade. Ele antes está pondo em cena o enfrentamento estratégico agonístico em constante reatualização, isto é, sem termo e sem conciliação.

A luta pela autonomia não traz descanso, repouso, consolação ou o prazer do fruto proibido, como na transgressão. Por essa razão, as resistências ao poder executadas por subjetividades distintas, com questões específicas e bastante distintas em níveis, gêneros e graus de complexidade inerentes à diversidade de faixas etárias e condições sociais, pressupõem combates agonísticos de diferentes matizes e gradações. Para Foucault, do ponto de vista filosófico, o ponto máximo ou mais acabado de resistência ao poder está na ontologia crítica do presente.

O conceito de ontologia histórica ou crítica do presente está diretamente vinculado a esse campo de atuação política iniciado na subjetividade e que incide necessariamente na vida coletiva e social, para além de toda e qualquer ideia de transgressão. No célebre texto 
Qu'est-ce que les Lumières (1984), após tematizar (e inverter, como Kant) as noções de razão pública e razão privada, Foucault define a questão do Aufklärung como "uma reflexão filosófica que diz respeito apenas ao modo de relação reflexiva com o presente" (FOUCAULT, 1994, p. 572). Em primeiro lugar, esse campo de atuação é definido como um ethos, uma atitude. Essa atitude, por sua vez, define-se como uma atitude-limite, ou seja, como a transformação de uma "crítica sobre a forma de limitação necessária [transmutada] em uma crítica prática na forma de uma ultrapassagem possível" (FOUCAULT, 1994, p. 574).

A ontologia crítica do presente não é uma tarefa fácil: tem como condição o diagnóstico, mais claro e racional possível, do mundo que cerca os indivíduos e, de maior ou menor forma, interfere em suas formas de ser e agir. Pressupõe a decisão sobre o campo a ultrapassar, os meios estratégicos dos quais os indivíduos podem dispor e também a superação de limites, que acaba repondo limites ao campo de superação já realizado. Desse modo, a luta pela ampliação da liberdade consiste em uma espécie de trabalho de Sísifo, no qual recomparece a todo momento a tarefa sempre inacabada de levar a liberdade a seu limiar. Cabe aos homens livres, a cada instante, reinventar suas formas de vida, seus valores autônomos, seus procedimentos e seus modos de agir e de conduzir suas vidas.

É digna de nota a homenagem que Foucault faz a Kant ao abordar o exercício da liberdade na modernidade. O Aufklärung, percebido não como um período da história, mas como uma atitude de modernidade que demanda um diagnóstico do presente histórico e das tarefas de libertação possíveis, implica um processo de autonomização no qual estão frente a frente, de maneira agonística, as formas possíveis de liberdade e o peso das relações de poder que fixam os sujeitos em campos de normalização e acomodação social. Se um indivíduo cria, de si para si, uma ética ou uma estética da existência, somente pode fazê-lo dando forma paciente à impaciência da liberdade.

A heterotopia de Foucault seria a governabilidade, entendida como o autogoverno de indivíduos livres e autônomos. Uma noção absolutamente paradoxal, uma vez que solicita alguma instância reguladora capaz de impedir que os combates agonísticos se convertam 
em guerra ou em outro modo de interferência na vida dos indivíduos, como as técnicas e os dispositivos de controle em ação na atualidade. Desse modo, a governabilidade tem sua contradição na governamentalidade. Na verdade, a governamentalidade é a forma de exercício do poder em sua versão liberal, burguesa, na qual cada cidadão é responsabilizado pelo comportamento dos outros e convocado ao exercício cotidiano do controle sobre si e sobre os demais membros da sociedade, em nome da segurança e da biopolítica.

Foucault estava atento ao fato de que o governo de homens livres, uns em face dos outros, comporta, em seus próprios fundamentos, a ameaça decorrente do caráter acontecimental das relações de poder:

não creio que o único ponto de resistência possível ao poder político compreendido, de maneira exata, como situação de dominação - esteja na relação de si para si. Digo que a governamentalidade implica a relação de si para consigo mesmo, o que significa dizer, exatamente, que nessa visão de governamentalidade estou falando do conjunto das práticas pelas quais é possível constituir, definir, organizar, instrumentalizar, as estratégias que os indivíduos, em sua liberdade, podem ter uns perante os outros. São indivíduos livres os que procuram controlar, determinar, delimitar a liberdade dos outros e, ao fazer isso, dispõem de certos instrumentos para governar os outros. Isso repousa tanto na liberdade quanto na relação consigo mesmo, assim como na relação com os outros (FOUCAULT, 1994, p. 728-729).

A liberdade, desse modo, pode trazer consigo as raízes de seu contrário. É por esse motivo que Foucault afirma que as lutas da modernidade são lutas que têm diante de si a contramodernidade.

Em seu projeto libertário, no entanto, nessa combinação peculiar de livre decisão e estratégia, muitos podem ter acesso comum, coletivo e solidário a patamares de autonomia considerados em uma esfera de sociabilidade não mais restritiva, na dependência inegável do grau de libertação realizado pelos membros da comunidade. Libertação que, nos termos de uma ética de inspiração kantiana, pressupõe limites advindos da própria realização da autonomia. Afinal, um homem que articula razão pública e privada no exercício de sua existência é aquele 
que delibera inicialmente consigo mesmo, tendo de vencer-se pela força da argumentação com a qual procura persuadir a si e aos demais e, desse modo, ajudar a transformar o campo social.

A liberdade, em seu exercício crítico e autônomo, não é plena e sem restrições: implica a obediência às máximas ditadas por sua tarefa crítica, advindas da reflexão sobre as ações possíveis criadas pelo presente histórico e político com o qual o indivíduo livre é obrigado a lidar e lutar. A hipótese que sustentamos é a de que, para que existam relações de poder nas quais os indivíduos sejam livres, tem que existir condições pessoais, sociais e políticas possíveis, sobretudo, na modernidade, que Foucault, em seus últimos cursos, mostrou que tinham raízes na Grécia Clássica.

A filosofia, que desde seu começo decorre de uma preocupação política, ${ }^{1}$ não nasceu sob o signo da pacificação nem se desenvolveu em um mundo social em harmonia absoluta. Oriunda de uma precária e frágil experiência democrática na Grécia Antiga, a tarefa maior da filosofia, desde sua origem, foi a de buscar constituir argumentos consistentes do ponto de vista da lógica do discurso e que, além disso, fossem socialmente aceitos, ao menos para uma parcela significativa do mundo social. Desde então, o pensamento luta para fazer valer as intelecções que realiza. Não é uma tarefa fácil empreender um campo de luta na teoria. Pede-se tomada de posição, capacidade persuasiva, espírito combativo e ligeiro.

Deleuze alerta que é característica da filosofia, desde a Grécia clássica, possuir essa dimensão agonística: "se a filosofia tem uma origem grega, como é certo dizê-lo, é porque a cidade, ao contrário dos impérios ou dos estados, inventa o agôn como regra de uma sociedade de 'amigos', a comunidade dos homens livres enquanto rivais (cidadãos). É a situação constantemente descrita por Platão: se cada cidadão aspira a alguma coisa, ele encontra necessariamente rivais" (DELEUZE; GUATARI, 1992, p. 17). Nesse aspecto, Deleuze

1 Os livros de Jean-Pierre Vernant sustentam essa hipótese, em especial o última parte de seu livro Mito e pensamento entre os gregos, quando aborda a passagem do mito à razão, de maneira que concorda, em muito por sinal, com as hipóteses sustentadas por Detienne, expostas em Os mestres da verdade na Grécia Arcaica.

Rev. Filos., Aurora, Curitiba, v. 23, n. 32, p. 145-155, jan./jun. 2011 
partilha da mesma visão sobre o papel da agonística que Foucault enxerga na vida social e política. ${ }^{2}$ Eu acrescentaria ainda que, se pensamento e luta fazem um par, decorre disso inexistir filosofia sem beligerância, sem rivalidade, sem disputa. Com a ressalva de que o inimigo maior da filosofia, assim, não é a luta argumentativa, nem o combate teórico, tampouco o adversário da filosofia é a doxa. ${ }^{3}$ Nosso maior adversário não é da ordem do pensamento, em que existe e deve existir certo grau de tolerância e rivalidade entre distintos modos de perceber as coisas.

O grande inimigo da filosofia, na verdade, é a violência cega, é a pura e simples truculência, são armas apontadas para as pessoas sem qualquer diálogo ou respeito, é todo constrangimento físico sem tirar nem pôr, é a pura arbitrariedade. A agonística entre ideias e formas de vida diferentes não é a verdadeira inimiga da filosofia e da democracia, mas o lugar natural e ponto de partida de seu exercício. Pensar e travar combates com outras ideias, pessoas e grupos sociais é uma necessidade. O que não pode acontecer é a paralisia das relações agonísticas, pois isso representaria a falta de mobilidade social e humana e privação de vivacidade democrática.

Foucault estava ciente da força desse novo modo de questionar a realidade social e de praticar a política a partir de seu cotidiano:

se se quer verdadeiramente criar algo de novo ou, em todo caso, se se quer que os grandes sistemas se abram, finalmente, para um certo número de problemas reais, deve-se procurar os dados e as questões ali onde eles estão. Assim, eu não penso que o intelectual possa, apenas a partir de suas pesquisas livrescas, acadêmicas e eruditas, levantar verdadeiras questões a respeito da sociedade na qual vive. Pelo contrário, uma das primeiras formas de colaboração com os não-intelectuais está exatamente em escutar seus problemas, e de trabalhar com eles para formulá-los: o que dizem os loucos? o que é a vida num hospital

2 Por esse motivo, torna-se engraçado ler intérpretes que veem em Deleuze um partidário do multiculturalismo. Para 0 filósofo, filosofia e luta são parceiros indissociáveis.

3 Nesse aspecto, certamente Chatelet discordaria de minha hipótese, pois ele, no Logos e práxis, sustenta que o homem da doxa afirma suas certezas, não quer discutir e tende, portanto, ao conflito (CHATELET, 1972, p. 89). 
psiquiátrico? qual é o trabalho de um enfermeiro? Como eles reagem? (FOUCAULT, 1994, p. 84).

Quem tem e deve ter a palavra, quem deve discutir e propor mudanças são as pessoas diretamente concernidas nas questões que os mobilizam, lá onde elas atuam. São as pessoas comuns, são os diversos profissionais que estão envolvidos em uma rotina de trabalho e nas relações de poder que ocorrem onde elas atuam. Somente eles podem falar sobre seus problemas e sobre o que deve ser modificado. Ninguém pode falar no lugar dos outros, pois são os profissionais e os militantes que sabem e conhecem o meio no qual estão e os fatos que ocorrem no seu cotidiano. A vida participativa decorre disso, é uma experiência que se faz no dia a dia, que é desafiadora e repleta de questões, de todas as ordens de grandeza a serem resolvidas, todas elas resultado da participação de todos os que fazem uso da palavra e partem para novas ações. Como lembra Philippe Artières, do Centre Michel Foucault, em um texto ainda inédito: “esta vinculação com a palavra das pessoas decorre, em Foucault, do mesmo questionamento que o levou a escrever a História da loucura: "o que é falar?". O que afeta Foucault nas agitações após maio de 68 é a tomada da palavra que se opera no movimento." ${ }^{4}$ Depois de gerações de silêncio, ao ver de Artières, as pessoas começaram, há poucas décadas, a fazer uso da palavra, a falar de seus problemas, a fazer reivindicações, a diminuir as distâncias, a exercer uma vida e uma palavra contestadora.

Nesse novo modo de pensar e de fazer política, não há como acreditar, como antes, em projetos unitários e gerais. $\mathrm{O}$ conceito de povo, e o da palavra do povo, passa a ser plural, o que implica, para a maioria, muitos riscos. Mas não vimos que a palavra e a política sempre trouxeram e ainda trazem o perigo e o risco? $\mathrm{O}$ risco, temos que ter esse fato sempre diante de nós, é signo da liberdade.

4 ARTIÉRES, P. Une politique du mineur. Texto inédito. 


\section{Referências}

ARTIÈRES, P. Une politique du mineur. 2009. Texto inédito.

CASTELO BRANCO, G. Foucault. In: PECORARO, R. (Org.). Os filósofos clássicos da filosofia. Rio de Janeiro: Ed. PUC-Rio; Vozes, 2009. v. 3, p. 280- 303.

CASTELO BRANCO, G. Anti-individualismo, vida artista: uma análise não-fascista de Michel Foucault. In: RAGO, M.; VEIGA-NETO, A. (Org.). Para uma vida não fascista. Belo Horizonte: Autêntica, 2009. p. 143-151.

CASTELO BRANCO, G. Agonística, relações de poder, liberdade. In: LUJÁN MARTÍNEZ, H. (Org.). Poder e política - Horizontes de antagonismo. Curitiba: CRV, 2010. p. 15-23.

CHATELET, F. Logos e práxis. Rio de Janeiro: Paz e Terra, 1972.

DETIENNE, M. Les maîtres de la verité dans la Gréce archaïque. Paris: La Decouverte, 1990.

DUARTE, A. Foucault e as novas figuras da biopolítica: o fascismo contemporâneo. In: RAGO, M.; VEIGA-NETO, A. (Org.). Para uma vida não-fascista. Belo Horizonte: Autêntica, 2009. p. 35-50.

DELEUZE, G.; GUATTARI, F. O que é a filosofia? São Paulo: Ed. 34, 1992.

FOUCAULT, M. Dits et écrits. 1954-1988. Paris: Gallimard, 1994.

FOUCAULT, M. L'herméneutique du sujet. Paris: Seuil, 2001.

FOUCAULT, M. Les anormaux. Paris: Seuil, 2001.

FOUCAULT, M. Naissance de la biopolitique. Paris: Seuil, 2004.

VERNANT, J-P. Mito \& pensamento entre os gregos. Rio de Janeiro: Paz e Terra, 2008.

Recebido: 20/11/2010

Received: $11 / 20 / 2010$

Aprovado: $10 / 02 / 2011$

Approved: 02/10/2011 